\title{
Incidence of sexual dysfunction: a prospective survey in Ghanaian females
}

\author{
Nafiu Amidu1*, William KBA Owiredu², Eric Woode 3 , Otchere Addai-Mensah', Lawrence Quaye², Abass Alhassan ${ }^{4}$, \\ Edmond A Tagoe ${ }^{5}$
}

\begin{abstract}
Background: Sexuality is a complex phenomenon that is being influenced by psychological as well as physiological factors. Its dysfunction includes desire, arousal, orgasmic and sex pain disorders. The present study aimed to assess the incidence of sexual dysfunction (SD) and related risk factors in a cohort of Ghanaian women.

Method: The Golombok Rust Inventory of Sexual Satisfaction (GRISS) was administered to 400 healthy women between 18 and 58 years old (mean +/- SD: 30.1 +/- 7.9) domiciled in the Kumasi metropolis.

Results: The response rate was $75.3 \%$ after 99 were excluded. Of the remaining 301 women, 50\% were engaged in exercise, $26.7 \%$ indulge in alcoholic beverages and only $2 \%$ were smokers. A total of $62.1 \%$ of the women had attained high education, whilst, 28.9\% were married. After logistic regression analysis, alcohol emerged (OR: 2.0; Cl: $1.0-3.8 ; p=0.04$ ) as the main risk factor for SD. The overall prevalence of SD in these subjects was $72.8 \%$. Severe difficulties with sexual function were identified in 3.3\% of the studied population. The most prevalent areas of difficulty were anorgasmia (72.4\%), sexual infrequency (71.4\%), dissatisfaction (77.7\%), vaginismus (68.1\%), avoidance of sexual intercourse (62.5\%), non-sensuality (61.5\%) and non-communication (54.2\%). Whereas $8 \%$ had severe difficulties with anorgasmia, only $6 \%$ had severe difficulties with vaginismus.
\end{abstract}

Conclusion: SD affects more than $70 \%$ of Ghanaian women who are sexually active. Alcohol significantly influences sexual activity.

\section{Background}

Human sexuality is a complex process which is coordinated by the neurologic, vascular and endocrine systems [1]. Sexuality does not only include family, societal and religious beliefs, it can also be influenced by aging, health status and personal experience as well as socioeconomic status. Sexual dysfunction (SD) is an important public health problem that is more prevalent in women than in men [2]. Previous studies have established that up to about $76 \%$ of women experience some form of SD - that is, a sexual problem that they find distressing [3].

The study and knowledge of SD has been largely unexplored and its incidence is said to vary widely possibly due to differences in criteria for defining SD: the

\footnotetext{
* Correspondence: nafamidu@yahoo.com

'Department of Medical Laboratory Technology, Faculty of Allied Health Sciences, College of Health Sciences, Kwame Nkrumah University of Science and Technology, Kumasi, Ghana

Full list of author information is available at the end of the article
}

population involved, cultural background, socio-economic level, quality of psychosexual relationships and income. An important development has been the classification of SD by the American Psychiatric Association documented in the Diagnostic and Statistical Manual of Mental Disorder (DSM-IV) [4]. The Diagnostic and Statistical Manual of Mental Disorders, 4th edition, text revision (DSM-IV-TR) identifies 6 female sexual dysfunctions: hypoactive sexual desire disorder, sexual aversion disorder, sexual arousal disorder, orgasmic disorder, dyspareunia and vaginismus (i.e. sexual pain disorders). Using these criteria, Laumann et al., found the prevalence of SD to be $43 \%$ in a survey of 1749 women aged 18 to 59 years in the United States [5]. SD was found to vary according to the physical and psychic health and ethnic group in this study [5]. In view of the reasons expressed above, the aim of this work was to study the incidence and type of sexual dysfunction in healthy sexually active Ghanaian women with a steady heterosexual relationship, and related risk factors. 


\section{Methods \\ Subjects}

Four hundred (400) Ghanaian women were randomly sampled in a cross-sectional study in the Kumasi metropolis, Ghana between December 2009 and May 2010. All the women reported a steady heterosexual relationship with one or more partners for more than one year. No woman had been a drug abuser or had surgical interventions which might modify sexual behaviour. Demographic and socio-cultural variables such as age, marital status, years of scholarship, smoking status, level of exercise and alcohol intake were recorded. Exercise was defined as any activity causing light perspiration or a slight to moderate increase in breathing or heart rate for at least 30 minutes. Alcohol intake was defined as the intake of at least one bottle of an alcoholic beverage per week. Regarding smoking, individuals were classified as smokers based on whether the respondent is in the habit of smoking at least one cigarette a day. Participation of the respondents was voluntary and informed consent was obtained from each participant. The study was approved by the Committee on Human Research, Publication and Ethics of the School of Medical Science and the Komfo Anokye Teaching Hospital, Kumasi.

\section{Sexual function}

This was assessed by the Golombok Rust Inventory of Sexual Satisfaction (GRISS). One of the main reasons for choosing the GRISS is its simplicity and clarity of the assessment of results. The GRISS has 28 items on a single sheet and it is used for assessing the existence and severity of sexual problems. All the 28 questions are answered on a five-point scale from "always", through "usually', "sometimes", and "hardly ever", to "never". Responses are summed up to give a total raw score (range 28-140). In addition, seven subscale scores are derived (i.e. vaginismus, anorgasmia, avoidance, nonsensuality, non-communication, infrequency and dissatisfaction). The total score and subscale scores are transformed using a standard nine point scale, with high scores indicating greater problems. Scores of five or more are considered to indicate sexual dysfunction. The reliability of the overall scales has been found to be 0.87 for women, and that of the subscales on average 0.74 (ranging between 0.61 and 0.83 ). Validity has been demonstrated under a variety of circumstances [6-8].

\section{Statistical analysis}

The data were presented as mean \pm SD or percentages. Continuous data were analyzed using unpaired $t$-tests whilst categorical variables were analyzed using Fischer's exact test or chi square for trend test. Logistic regression was used to assess the simultaneous influence of different variables in sexuality. In all statistical tests, a value of $p<0.05$ was considered significant. The entry of the variables into the model was considered if $\mathrm{p}$ value is less than 0.05, and a stepwise procedure was applied. All analysis were performed using SigmaPlot for Windows, Version 11.0, (Systat Software, Inc. Germany) [9]

\section{Results}

Of the initial 400 women recruited, 99 were excluded: 11 had severe chronic disease, 16 denied participations, 31 had difficulties in understanding the survey and the questionnaires from 41 women were incomplete, leaving 301 complete and evaluable questionnaires, indicating a response rate of $75.3 \%$. The mean age of the participating women was $30.1 \pm 7.9$ years. The median age was 28.0 years with inter-quartile range of 25.0 to 34.0 and age range of 18 to 58 years. Almost $50 \%$ of the women were engaged in exercise, $26.7 \%$ indulge in alcoholic beverages and only $2 \%$ were smokers. A total of $62.1 \%$ of the women had attained high education, whilst $28.9 \%$ were married. About $18 \%$ of the participating women were 36 years or older.

The effect of different socio-demographic variables on the SD risk is recorded in Table 1 . The only significant factor from this study that increased female SD as determined by univariate analysis was alcohol (OR: 2.0; CI: 1.1 - 3.9; $\mathrm{p}=0.03)$. None of the other factors modified SD risk significantly (Table 1 ). After logistic regression analysis, alcohol still emerged (OR: 2.0; CI: 1.0 - 3.8; $\mathrm{p}=0.04)$ as the main risk factor for SD.

\begin{tabular}{|c|c|c|c|c|}
\hline Variables & $\mathrm{n} / \mathrm{N}^{*}$ & Rate of SD (\%) & $\mathrm{OR}(\mathrm{Cl} 95 \%)$ & $P$ value \\
\hline \multicolumn{5}{|l|}{ Exercise } \\
\hline Yes & $109 / 149$ & 73.2 & $1.0(0.6-1.7)$ & 0.9 \\
\hline No & $107 / 150$ & 71.3 & & \\
\hline \multicolumn{5}{|l|}{ Alcohol } \\
\hline Yes & $66 / 80$ & 82.5 & $2.0(1.1-3.9)$ & 0.03 \\
\hline No & $151 / 220$ & 68.6 & & \\
\hline \multicolumn{5}{|l|}{ Smoking } \\
\hline Yes & $6 / 6$ & 100.0 & $1.0(0.3-90.7)$ & 0.2 \\
\hline No & $212 / 294$ & 72.1 & & \\
\hline \multicolumn{5}{|l|}{ Married } \\
\hline Yes & $84 / 87$ & 96.6 & $1.2(0.7-2.1)$ & 0.6 \\
\hline No & $135 / 214$ & 63.1 & & \\
\hline \multicolumn{5}{|c|}{ Educational attainment } \\
\hline High & $131 / 187$ & 70.1 & $1.6(0.9-2.7)$ & 0.1 \\
\hline Low & $88 / 114$ & 77.2 & & \\
\hline \multicolumn{5}{|c|}{ Age $\geq 36$ years } \\
\hline Yes & $37 / 53$ & 69.8 & $1.3(0.7-2.5)$ & 0.4 \\
\hline No & $182 / 247$ & 73.7 & & \\
\hline
\end{tabular}

${ }^{*}$ Number of subjects with SD/number of subjects in each category. 


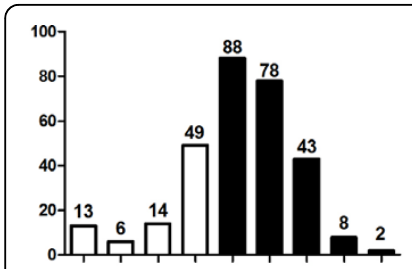

Sexual dysfunction

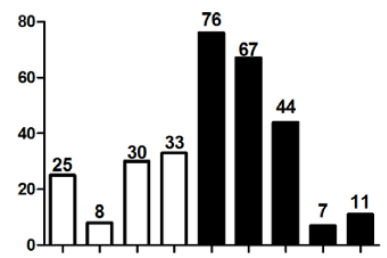

Vaginismus

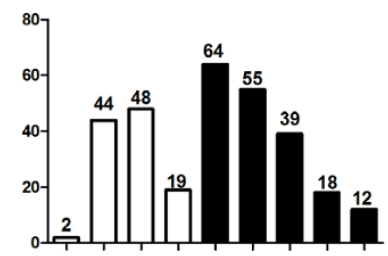

Avoidance

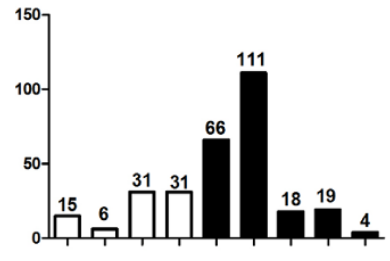

Anorgasmia

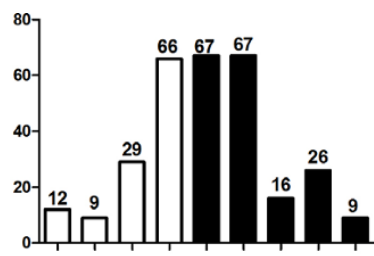

Non-sensuality

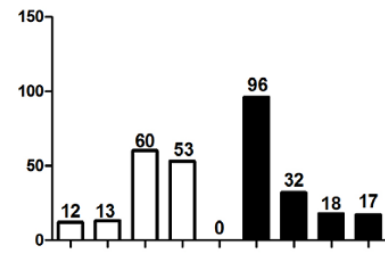

Non-communication

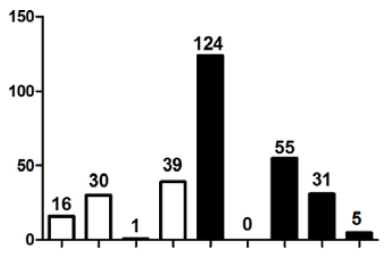

Infrequency

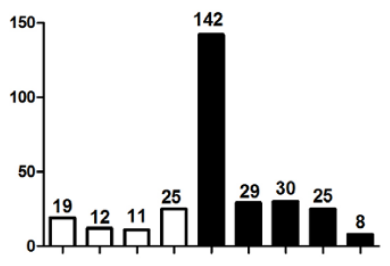

Dissatisfaction

Figure 1 Participants' sexual function scores for each GRISS subscale $(\mathbf{n}=\mathbf{3 0 1}$ ). Each graph shows the distribution of scores (from 1 to 9 on the $x$-axis) for each GRISS subscale, with the number of women (y-axis) above each score. Normal scores are 1 to 4 (clear columns) and abnormal scores are 5 to 9 (black columns).

Most of the women (219 out of 301; 72.8\%) had one or more subscale scores reflecting sexual problems (score of 5 or above). The most prevalent areas of sexual difficulty (Figure 1) were dissatisfaction (234 out of 301; $77.7 \%$ ), anorgasmia (218 out of $301 ; 72.4 \%$ ), sexual infrequency (215 out of 301; 71.4\%), vaginismus (205 out of $301 ; 68.1 \%$ ), avoidance, of sexual intercourse (188 out of $301 ; 62.5 \%$ ), and non-sensuality (185 out of $301 ; 61.5 \%$ ). The levels of communication scores were relatively high, with only $54.2 \%$ of the participants having a score indicating non-communication. However, $3.3 \%$ (i.e. 10 out of 301) of the studied population had severe SD. About $12 \%$ had severe difficulties with sensuality, frequency and communication. Eleven percent $(11 \%)$ and $10 \%$ had severe difficulties with satisfaction and avoidance respectively. Whereas $8 \%$ had severe difficulties with anorgasmia, only $6 \%$ had severe difficulties with vaginismus (Figure 1).

When the study population was stratified by age, the prevalence of SD generally remained stable (i.e. around 73\%). A marked decrease and increase in the prevalence of SD is however noted in the 38 to 42 years group and $\geq 48$ year groups respectively. Out of the seven subscales, only vaginismus was observed to significantly increase with age (Table 2).

SD correlated with non-sensuality, vaginismus, anorgasmia and dissatisfaction with a large size effect. As can be seen in Table 3, most of the areas of sexual function were related, with small to large effect sizes [10]. For the purpose of interpretation, Cohen [10] considered $0.10<r<0.30$ as small, $0.30<r<0.50$ as medium and $\mathrm{r}>0.50$ as large. Women with sexual dissatisfaction were also more likely to have problems with all the other subscales apart from avoidance $(r=0.07)$. Women with anorgasmia were more likely to have avoidance of sexual activity $(r=0.13, P<0.05)$, non-sensuality $(\mathrm{r}=$ $0.42, \mathrm{P}<0.0001)$, decreased frequency of sexual activity $(\mathrm{r}=0.21, \mathrm{P}<0.0001)$ and vaginismus $(r=0.44, P<$ $0.0001)$. Vaginismus also increased with increased nonsensuality $(\mathrm{r}=0.37, \mathrm{P}<0.0001)$ and infrequency $(\mathrm{r}=$ $0.12, \mathrm{P}<0.05$ ) (Table 3).

\section{Discussion}

It is noteworthy that a sexual problem is perceived as a disorder only if a woman perceives it to be so, with impaired sexual desire as the most common presentation [11]. Sexual problems in women may contribute to infertility, emotional burden, health burden and a burden on the relationship. Emotional burdens may lead to a sense of embarrassment and awkwardness because of difficulty in satisfying the partner.

In assessing six socio-demographic factors (exercise, alcohol, smoking, marital status, educational status and age) as risk factors for female sexual dysfunction, alcohol intake was the sole significant risk factor for the development of sexual dysfunction in this study. Female respondents who took alcoholic beverages were 2 times at risk of developing sexual dysfunction than those who were not taking alcoholic beverages. Alcohol is known to reduce genital response $[12,13]$ and this might be a reason for the significant increase in the rate of sexual dysfunction observed in the study respondents taking alcoholic beverages. It is also possible that women who consume alcoholic beverages in connection with sexual 
Table 2 Prevalence of sexual dysfunction according to age group using GRISS

\begin{tabular}{|c|c|c|c|c|c|c|c|c|}
\hline \multirow[b]{2}{*}{ Variable } & \multicolumn{7}{|c|}{ Age (years) } & \multirow[b]{2}{*}{$\begin{array}{c}P \\
\text { value }\end{array}$} \\
\hline & $\begin{array}{l}18- \\
22\end{array}$ & $\begin{array}{l}23- \\
27\end{array}$ & $\begin{array}{l}28- \\
32\end{array}$ & $\begin{array}{l}33- \\
37\end{array}$ & $\begin{array}{c}38- \\
42\end{array}$ & $\begin{array}{c}43- \\
47\end{array}$ & $\begin{array}{c}\geq \\
48\end{array}$ & \\
\hline$n$ & 38 & 94 & 78 & 41 & 21 & 13 & 14 & \\
\hline \multicolumn{9}{|c|}{ Difficulties (\%) } \\
\hline $\begin{array}{l}\text { Sexual } \\
\text { dysfunction }\end{array}$ & 73.7 & 72.3 & 73.1 & 73.2 & 57.1 & 76.9 & 85.7 & 0.9 \\
\hline Avoidance & 76.3 & 64.9 & 57.7 & 56.1 & 47.6 & 92.3 & 57.1 & 0.3 \\
\hline Non-sensuality & 52.6 & 61.7 & 65.4 & 68.3 & 47.6 & 69.2 & 50.0 & 1.0 \\
\hline Infrequency & 65.8 & 69.1 & 80.8 & 75.6 & 52.4 & 61.5 & 71.4 & 0.8 \\
\hline Vaginismus & 65.8 & 63.8 & 66.7 & 65.9 & 81.0 & 76.9 & 85.7 & 0.04 \\
\hline Anorgasmia & 71.2 & 70.2 & 74.4 & 68.3 & 66.7 & 92.3 & 85.7 & 0.2 \\
\hline $\begin{array}{l}\text { Non- } \\
\text { communication }\end{array}$ & 52.6 & 56.4 & 52.6 & 48.8 & 71.4 & 53.8 & 42.9 & 0.9 \\
\hline Dissatisfaction & 71.1 & 74.5 & 84.6 & 80.5 & 76.2 & 76.9 & 71.4 & 0.7 \\
\hline \multicolumn{9}{|c|}{ Severe difficulties $(\%)^{* *}$} \\
\hline $\begin{array}{l}\text { Sexual } \\
\text { dysfunction }\end{array}$ & 2.6 & 5.3 & 2.6 & 4.9 & 0.0 & 0.0 & 0.0 & 0.3 \\
\hline Avoidance & 21.1 & 12.8 & 5.1 & 2.4 & 4.8 & 7.7 & 21.4 & 0.2 \\
\hline Non-sensuality & 10.5 & 14.9 & 11.5 & 14.6 & 4.8 & 0.0 & 7.1 & 0.2 \\
\hline Infrequency & 13.2 & 11.7 & 11.5 & 7.3 & 14.3 & 15.4 & 21.4 & 0.6 \\
\hline Vaginismus & 0.0 & 8.5 & 2.6 & 9.8 & 4.8 & 7.7 & 14.3 & 0.2 \\
\hline Anorgasmia & 5.3 & 9.6 & 10.3 & 7.3 & 0.0 & 0.0 & 7.1 & 0.4 \\
\hline $\begin{array}{l}\text { Non- } \\
\text { communication }\end{array}$ & 13.2 & 14.9 & 9.0 & 14.6 & 9.5 & 7.7 & 0.0 & 0.2 \\
\hline Dissatisfaction & 10.5 & 13.8 & 9.0 & 14.6 & 9.5 & 0.0 & 7.1 & 0.3 \\
\hline
\end{tabular}

*Score of 5-9 and ${ }^{* *}$ Score of 8 or 9. P values were derived from chi square for trend.

activities may initially have sexual function problems and, therefore, consume alcohol in order to reduce anxiety which might further increase the risk of sexual dysfunction.

A study conducted by Amidu et al., (under review) on Ghanaian perceptions on intravaginal ejaculatory latencies established that, women, desire that intercourse lasts about twice ( $8-19$ minutes) as long as what sex therapists consider to be adequate ( $3-7$ minutes). A sexual performance level below this perceived duration may therefore lead to distress and displeasure which ultimately results in the use of varied remedies to restore performance levels. Patronage of aphrodisiacs which are mostly formulated in alcoholic base in Ghana is on the ascendancy (personal observation) and their chronic usage may increase the risk of sexual dysfunction as established in this study. The other socio-demographic variables when assessed as risk factors for female sexual dysfunction did not contribute significantly to the rate of developing sexual dysfunction from this study.

The prevalence rate of sexual dysfunction was $73 \%$ in females in this study and this finding is consistent with that of Frank et al., [14] and Spector et al., [3] who reported prevalence rates of $76 \%$ in women. Such a high rate of sexual dysfunction may compromise the health status and quality of life of women due to a general sense of embarrassment, awkwardness and the inability to satisfy their partners fully. The most common female SD problems in this study were sexual dissatisfaction (77.7\%), anorgasmia (72.4\%) and sexual infrequency (71.4\%). Jindal et al., [15] in an evaluation of 200 Indian women reported sexual infrequency and anorgasmia as the most common problems.

Sexual dissatisfaction could be multifactorial in nature and the varied causes were not explored by this prospective survey. However, the high perception of women on the length of ejaculatory latencies coupled with a reported premature-like ejaculation prevalence of $64.7 \%$ in Ghanaian men (Amidu et al., under review) could play a significant role in the observation that women do not achieve adequate satisfaction and gratification from their partners during sexual intercourse. A general lack or reduced sexual satisfaction could thus lead to anorgasmia and sexual infrequencies as observed in the percentage prevalence. Sexual trauma resulting from rape is a significant contributing factor for the high incidence of anorgasmia. Sexual trauma results in increased risk of

Table 3 Pearson Product Moment Correlation Coefficient Between Female Sexual Dysfunction Including the 7 Subscales of the GRISS $(N=301)$

\begin{tabular}{|c|c|c|c|c|c|c|c|c|}
\hline Variables & SD & AV & NS & INF & VAG & ANG & NC & DIS \\
\hline Age & 0.04 & $-0.12^{*}$ & 0.00 & 0.05 & $0.15^{* *}$ & 0.09 & -0.02 & 0.05 \\
\hline Sexual dysfunction (SD) & & $0.30^{* * *}$ & $0.67^{* * *}$ & $0.36^{* * *}$ & $0.62^{* * *}$ & $0.70^{* * *}$ & $0.32^{* * *}$ & $0.62^{* * *}$ \\
\hline Avoidance (AV) & & & -0.03 & -0.09 & 0.01 & $0.13^{*}$ & 0.07 & 0.07 \\
\hline Non-sensuality (NS) & & & & $0.17^{* *}$ & $0.37^{* * *}$ & $0.42^{* * *}$ & $0.14^{*}$ & $0.30^{* * *}$ \\
\hline Infrequency (INF) & & & & & $0.12^{*}$ & $0.21^{* * *}$ & $0.14^{*}$ & $0.21^{* * *}$ \\
\hline Vaginismus (VAG) & & & & & & $0.44^{* * *}$ & $0.12^{*}$ & $0.27^{* * *}$ \\
\hline Anorgasmia (ANG) & & & & & & & 0.10 & $0.31^{* * *}$ \\
\hline Non-communication (NC) & & & & & & & & $0.16^{* *}$ \\
\hline
\end{tabular}

${ }^{*}$ Correlation is significant at the 0.05 level (2-tailed), ${ }^{* *}$ Correlation is significant at the 0.01 level (2-tailed), ${ }^{* * *}$ Correlation is significant at the 0.001 level (2-tailed). Boldface $r=$ Pearson product moment correlation coefficient with a medium size $(0.30 \leq r \geq 0.50)$ effect: boldface and italiced $r=$ Pearson product moment correlation coefficient with a large size $(r>0.50)$ effect, DIS = dissatisfaction. 
experiencing arousal disorders and this induces lasting psychosocial disturbances which ultimately affects sexual function and its related orgasmic disorders [16]. Sexual infrequency may be a problem in its own right and may possibly be influenced by both health related and psychosocial factors [5]. Stress induced events as a result of psychosocial factors and interplay of a host of other factors not explored by this study may reduce opportunities for sexual interaction [5].

The prevalence of vaginismus from this study was $68.1 \%$ and this is consistent with the finding of Tayebi et al., [17] which reported a percentage of 67.7. The prevalence rates of the other subscales are: avoidance of intercourse $(62.5 \%)$, non-sensuality $(61.5 \%)$ and noncommunication (54.2\%).

The high prevalence of SD observed in the $\geq 48$ year group may be attributed mostly to vaginismus which showed a significantly high prevalence in comparison to the other areas of sexual difficulty and a positive linear relationship with a small size effect to age. Vaginismus would therefore tend to increase with increasing age. Laumann et al., [5] in his study findings, stated that prevalence of sexual problems decrease with increasing age except for those who have some difficulties with lubrication. Lubrication is required for smooth and enjoyable sexual intercourse and as such inadequate lubrication is associated with vaginismus in the $\geq 48$ year group. Oberg et al., [18] in a study on women aged 18-65 found vaginismus to be strongly associated with sexual distress.

Furthermore, vaginismus had a small size linear effect with sexual infrequency and a large sized linear effect with non-sensuality. This means that respondents in the $\geq 48$ year group will often tend to have infrequent sexual activities and waning sexual desire as a result of vaginismus. Hayes et al., [19] reported a linear decrease in desire with increasing age from 20 to 70 and Abdo et al., [20] reported a general negative effect of age on desire and a positive effect on pain and these findings are consistent with that of this study.

Non-communication showed the least prevalence amongst the areas of sexual difficulty and correlated linearly to a small size effect with dissatisfaction, vaginismus, sexual infrequency and non-sensuality. Decreased partner interaction and lack of communication in the relationship will therefore most certainly be linked with lack of desire, sexual infrequency, sexual dissatisfaction and vaginismus. Byers, [21] showed intimate communication to be associated with changes in both relationship and sexual satisfaction over a time period of 18 months. Others reporting on poor communication also reported a decrease in both relationship and sexual satisfaction during this time period while those reporting good communication reported an increase.
King et al., [22] reported that having one SD is commonly associated with a secondary SD. Significant comorbidities were observed between the subscales of SD assessed in this study. Sexual dissatisfaction correlated with non-sensuality and anorgasmia on a large size scale and sexual infrequency, vaginismus and non-communication on a small size scale. Sexual dissatisfaction often leads to loss of sensuality and subsequent orgasmic disorders which results in ripple effects of sexual infrequencies, sexual pains and a general lack of communication in the relationship $[19,23]$.

Non-communication on the other hand correlated on a small size scale with non-sensuality, sexual infrequency and vaginismus. Poor communication in a relationship may lead to reduced sexual desire, infrequent sexual episodes and a resultant sexual pain. Anorgasmia correlated with non-sensuality and vaginismus to a large size effect whereas infrequency and avoidance correlated on a small size effect. Reduced sensuality for a partner wanes desire for sexual intercourse which culminates in orgasmic disorders and pain during sex [24]. Such episodes may lead to sexual infrequencies and a general avoidance of sexual intercourse with the partner. Vaginismus correlated on a large size effect with non-sensuality and on a small size effect with sexual infrequency. Women will therefore tend to have vaginismus when there is reduced sensuality which could further lead to sexual infrequency. Sexual infrequency correlated with non-sensuality on a small size effect and certainly so, lack of desire for a partner in a relationship could lead to infrequent sexual acts. It is, however, worthy to note that such existent correlations do not imply causality but it is reasonable to assume that one variable could result in the other, e.g., suffering from sexual pain will result in sexual dissatisfaction and on the other hand being dissatisfied and anxious about sexual activities or one's sexuality might also result in pain.

\section{Conclusion}

In an overall analysis, sexual dissatisfaction had the highest prevalence and the highest co-morbidity with the other risk factors of SD making it a worthy risk factor to investigate and addressed thoroughly as a totality of such risk factors culminating in SD could lead to low feelings of physical and emotional satisfaction and low feelings of happiness and a general diminished quality of life in women. Alcohol is a significant risk factor for developing sexual dysfunction.

\section{Author details}

${ }^{1}$ Department of Medical Laboratory Technology, Faculty of Allied Health Sciences, College of Health Sciences, Kwame Nkrumah University of Science and Technology, Kumasi, Ghana. ${ }^{2}$ Department of Molecular Medicine, School of Medical Sciences, College of Health Sciences, Kwame Nkrumah University 
of Science and Technology, Kumasi, Ghana. ${ }^{3}$ Department of Pharmacology, Faculty of Pharmacy and Pharmaceutical Science, College of Health Sciences, Kwame Nkrumah University of Science and Technology, Kumasi, Ghana. ${ }^{4}$ Laboratory Department, Kwame Nkrumah University of Science and Technology Hospital, Kumasi, Ghana. ${ }^{5}$ Department of Obstetrics and Gynaecology, Kwame Nkrumah University of Science and Technology Hospital, Kumasi, Ghana.

\section{Authors' contributions}

NA, WKBAO and EW developed the concept and designed the study. NA, WKBAO, EW, OA-M, LQ, AA and EAT administered the questionnaire, analysed and interpreted the data. NA, OA-M, LQ, AA and EAT drafted the manuscript. NA, WKBAO, EW, OA-M, LQ, AA and EAT revised the manuscript for intellectual content. All authors read and approved the final manuscript.

\section{Competing interests}

The authors declare that they have no competing interests.

Received: 30 July 2010 Accepted: 1 September 2010 Published: 1 September 2010

\section{References}

1. Drench ME, Losee RH: Sexuality and sexual capacities of elderly people. Rehabil Nurs 1996, 21(3):118-123.

2. Laumann EO, Nicolosi A, Glasser DB, Paik A, Gingell C, Moreira E, Wang T: Sexual problems among women and men aged $40-80 \mathrm{y}$ : prevalence and correlates identified in the Global Study of Sexual Attitudes and Behaviors. Int J Impot Res 2005, 17(1):39-57.

3. Spector IP, Carey MP: Incidence and prevalence of the sexual dysfunctions: a critical review of the empirical literature. Arch Sex Behav 1990, 19(4):389-408.

4. APA: Diagnostic and Statistical Manual of Mental Disorders. Washington DC: American Psychiatric Association (APA), 4 2000, text rev.

5. Laumann EO, Paik A, Rosen RC: Sexual dysfunction in the United States: prevalence and predictors. JAMA 1999, 281(6):537-544.

6. Rust J, Golombok S: The GRISS: a psychometric instrument for the assessment of sexual dysfunction. Arch Sex Behav 1986, 15(2):157-165.

7. Rust J, Golombok S: the Golombok Rust Inventory of Sexual Satisfaction (GRISS) [manual]. Windsor, England: NFER: Nelson 1986.

8. Rust J, Golombok S: The Golombok-Rust Inventory of Sexual Satisfaction (GRISS). Br J Clin Psychol 1985, 24(Pt 1):63-64.

9. SigmaPlot for Windows: Version 11.0, (Systat Software, Inc. Germany). [http://www.systat.com].

10. Cohen J: Statistical power analysis for the behavioral sciences. New York: New York: Academic Press 1977.

11. Reader F: Disorders of female sexuality. In Progress in obstetrics and gynaecology. Edited by: Stud J. London: Churchill Livingstone; 1991:9:303-317.

12. Covington SS, Kohen J: Women, alcohol, and sexuality. Adv Alcohol Subst Abuse 1984, 4(1):41-56.

13. George WH, Stoner SA: Understanding acute alcohol effects on sexual behavior. Annu Rev Sex Res 2000, 11:92-124.

14. Frank $E$, Anderson $C$, Rubinstein D: Frequency of sexual dysfunction in "normal" couples. N Engl J Med 1978, 299(3):111-115.

15. Jindal UN, Dhall GI: Psychosexual problems of infertile women in India. Int J Fertil 1990, 35(4):222-225.

16. Browning CR, Laumann EO: Sexual Contact between Children and Adults: A Life Course Perspective. American Sociological Review 1997, 62(4):540-560

17. Tayebi N, Ardakani SMY: Incidence and Prevalence of the Sexual Dysfunctions in Infertile Women. Eur J Gen Med 2009, 6(2):74-77.

18. Oberg K, Fugl-Meyer AR, Fugl-Meyer KS: On categorization and quantification of women's sexual dysfunctions: an epidemiological approach. Int J Impot Res 2004, 16(3):261-269.

19. Hayes RD, Dennerstein L, Bennett CM, Sidat M, Gurrin LC, Fairley CK: Risk factors for female sexual dysfunction in the general population: exploring factors associated with low sexual function and sexual distress. J Sex Med 2008, 5(7):1681-1693.

20. Abdo CH, Oliveira WM Jr, Moreira ED Jr, Fittipaldi JA: Prevalence of sexual dysfunctions and correlated conditions in a sample of Brazilian women- results of the Brazilian study on sexual behavior (BSSB). Int I Impot Res 2004, 16(2):160-166.

21. Byers ES: Relationship satisfaction and sexual satisfaction: a longitudinal study of individuals in long-term relationships. I Sex Res 2005, 42(2):113-118.

22. King M, Holt $V$, Nazareth I: Women's views of their sexual difficulties: agreement and disagreement with clinical diagnoses. Arch Sex Behav 2007, 36(2):281-288.

23. Lutfey KE, Link CL, Rosen RC, Wiegel M, McKinlay JB: Prevalence and correlates of sexual activity and function in women: results from the Boston Area Community Health (BACH) Survey. Arch Sex Behav 2009, 38(4):514-527.

24. Graham CA, Sanders SA, Milhausen RR, McBride KR: Turning on and turning off: a focus group study of the factors that affect women's sexual arousal. Arch Sex Behav 2004, 33(6):527-538.

doi:10.1186/1477-7827-8-106

Cite this article as: Amidu et al:: Incidence of sexual dysfunction: a prospective survey in Ghanaian females. Reproductive Biology and Endocrinology 2010 8:106.

\section{Submit your next manuscript to BioMed Central and take full advantage of:}

- Convenient online submission

- Thorough peer review

- No space constraints or color figure charges

- Immediate publication on acceptance

- Inclusion in PubMed, CAS, Scopus and Google Scholar

- Research which is freely available for redistribution 